\title{
PLANEJAMENTO DOCENTE COMO PRODUÇÃO DE POSSÍVEIS:
} re-existência na/pela docência

\author{
Izaque Moura de Faria \\ Larissa Ferreira Rodrigues Gomes
}

\begin{abstract}
Resumo
O artigo é fragmento de uma pesquisa concluída e debate a potência do planejamento docente como produtor de possíveis na tessitura curricular e constituição da docência. Destaca a ação docente de ensaiar, de preparar-se para a aula como modo de re-existir através da/na docência, rompendo com perspectivas eficienticistas, burocráticas e individualizadas de idealização da aula e do currículo. Trata de uma pesquisaintervenção cartográfica produzida-efetuada no cotidiano de uma Escola Municipal de Ensino Fundamental de Serra/Espírito Santo, em 2019. Dialoga com os conceitos de agenciamento coletivo de enunciação e redes de conversações afirmando o planejamento docente como composição de heterogeneidades expressivas que perpassam a docência enquanto relação de aprenderensinar. Ressalta a produção de possíveis através do planejamento docente como meio de expandir currículos e docências para além do estabelecido. Palavras-chave: planejamento docente; ensaio; docência
\end{abstract}

\section{TEACHING PLANNING AS PRODUCTION OF POSSIBLES:} re-existence in/through teaching

\begin{abstract}
The article is a fragment of a completed research and discusses the power of teaching planning as a producer of possibles in the curricular fabric and teaching constitution. It highlights the teaching action of rehearsing, of preparing for class as a way of re-existing in/through teaching, breaking with efficient, bureaucratic and individualized perspectives of the idealization of the class and the curriculum. It deals with a cartographic research-intervention produced-effected in the daily life of a Municipal Elementary School in Serra / Espírito Santo, in 2019. Dialogues with the concepts of collective enunciation agency and conversation networks affirming teaching planning as a composition of expressive heterogeneities that permeate teaching as a relationship of learning-teach. It emphasizes the production of possibles through teacher planning as a means of expanding curricula and teaching beyond what is established.
\end{abstract}

Keywords: teaching planning; rehearsal; teaching

\section{PLANIFICACIÓN DOCENTE COMO PRODUCCIÓN DE POSIBLES:} reexistencia en/a través de la enseñanza

Resumen

El artículo es un fragmento de una investigación completa y analiza el poder de la planificación docente como productora de posibilidades en el tejido curricular y la constitución docente. Destaca la acción docente de ensayar, de prepararse para la clase como una forma de reexistir a través de la enseñanza, rompiendo con las perspectivas eficientes, burocráticas e individualizadas de la idealización de la clase y el currículo. Se trata de una investigación-intervención cartográfica producida-realizada en la vida cotidiana de una Escuela Primaria Municipal de Serra / Espírito Santo, en 2019. Diálogos con los conceptos de agencia colectiva de enunciación y redes de conversación afirmando la planificación de la enseñanza como una composición de heterogeneidades expresivas que permean la enseñanza como relación de aprender-enseñar. Enfatiza la producción de posibles a través de la planificación docente como un medio para ampliar los currículos y la enseñanza más allá de lo establecido.

Palabras clave: planificación docente; ensayo; acto de enseñar 


\section{INTRODUÇÃO}

As linhas aqui rascunhadas se apresentam como possibilidades imanentes de pensar/produzir a aula como um intenso ato docente de preparar-se para viverpraticar os acontecimentos com os cotidianos escolares. Rascunhos considerados não como algo "inferior", mas como movimento de ampliar os sentidos quanto à potência do planejamento docente como produtor de possíveis - que no encontro com o outro, seus signos e enunciados, produz disponibilidade para deixar algo passar, acontecer - na constituição curricular e na docência, ambos imbricados com a produção de conbecimentossignificações ${ }^{2}$ (ALVES, 2019) que mobilizem nas/os ${ }^{3}$ praticantespensantes $^{4}$ (OLIVEIRA, 2012) da escola o desejo por uma vida mais comprometida com a coletividade.

Desejo como construção a partir do que há ao invés de busca pelo que falta, e que como todo agenciamento, é coletivo (DELEUZE, GUATTARI, 1995b) e constitui uma composição redundante de agenciamentos coletivos de enunciação ${ }^{5}$ e atos (agenciamentos maquínicos), em que a noção de agenciamento coletivo de enunciação é a mais importante, já que advém dela o caráter social do agenciamento enunciado-efetuado. Assim, interessa neste artigo, destacar o conceito de planejamento docente expandido - pelo viés dos agenciamentos coletivos de enunciação e das "redes de conversações" (CARVALHO, 2009) estabelecidas em um cotidiano escolar de pesquisaintervenção - para além dos sentidos de processo técnico, eficienticista e burocrático, conectandoo ao sentido que Gilles Deleuze (1994) confere ao ensaio: um esforço de abrir-se, criar disponibilidade aos possíveis.

Expansão conceitual produzida através de uma performance metodológica cartográfica fortemente implicada pela filosofia da diferença, mais especificamente, pelos estudos de Gilles Deleuze e Félix Guattari (1995a, 1995b). Uma metodologia que “[...] pressupõe uma orientação do trabalho do pesquisador que não se faz de modo prescritivo, por regras já prontas, nem com objetivos previamente estabelecidos" (PASSOS, BARROS, 2015, p. 17), mas num duplo movimento de pesquisar-intervir. Em que a "[...] desterritorialização e reterritorialização"

\footnotetext{
${ }^{1}$ Propondo a superação de dicotomias - a exemplo de Nilda Alves (2019) - optamos pela fusão de alguns termos, ao longo desta escrita, indicando a simultaneidade em que se dão os processos em educação.

2 Conforme Nilda Alves (2019), ao produzirmos e expandirmos conhecimentos, simultaneamente produzimos e expandimos suas significações para o cotidiano de relações e acontecimentos em que tais conbecimentossignificações são produzidos, expandidos, enunciados, agenciados. Conhecimentossignificações que constituem processos e não produtos.

${ }^{3}$ Concordando com Abranches (2009, p. 18), sempre que preciso será utilizado ao longo do texto a barra para fazer "[...] referência explícita a ambos os sexos de forma igual e paralela, o que implica tornar visível na linguagem o sexo invisível - na grande maioria dos casos, as mulheres - através da marcação sistemática e simétrica do gênero gramatical".

${ }^{4}$ Praticantespensantes que fazem a escola cotidianamente (OLIVEIRA, 2012). Termo utilizado por Oliveira, a partir dos estudos de Michel de Certeau, que aqui mobiliza o sentido de produzir-efetuar docências a cada encontro entre si, pois a docência se dá no encontro, ela é relação de aprenderensinar entre suas/eus praticantespensantes: professoras/es e estudantes.

${ }^{5}$ Construção coletiva constituída tão somente de enunciados e signos de um discurso sempre indireto (DELEUZE, GUATTARI, 1995b), composição de heterogeneidades sem um enunciador particular pois é sempre processo mobilizado pela/na coletividade.

6 Redes de conversações e ações complexas que, segundo Carvalho (2009, p. 188-189), utilizam “[...] metodologicamente as conversações como uma tática da discursividade local, acompanhando os fluxos das conversações tecidas em redes de subjetividades compartilhadas", o que possibilita discutir práticaspoliticas possíveis para os currículos nos cotidianos escolares.
}

Revista Teias v. 21 • n. 63• out./dez. 2020 • Seção Temática Docência, currículo, didática, aula: fantástico arquivo político da diferença 
(DELEUZE; GUATTARI, 1995a) do conceito de planejamento docente, seguiu linhas, traçou mapas, capturou pistas e produziu enunciações em um território escolar de ensino fundamental em Serra / Espírito Santo, no ano de 2019, problematizando como o planejamento docente pode produzir possíveis nas práticas educativas.

Neste sentido, primeiramente, o artigo destaca o processo de "erosão" do conceito de planejamento docente que, desconfiando da pretensa homogeneidade que a modernidade lhe atribui problematiza e esgarça este conceito para além de suas expressões corriqueiras de produto a ser aplicado sobre a aula, currículos e docências; distante da imanência da escola e componente do ciclo planejar, executar e avaliar. Em seguida, ressalta a relevância do ensaio docente como intenso exercício de preparação e de abertura aos possíveis, que através dos agenciamentos coletivos de enunciação, provoca o ato criativo e a capacidade de mobilizar pensamentos, variabilidades, heterogeneidades de signos e enunciados possíveis nas práticas educativas. Por fim, afirma a potência do planejamento docente como resistência ao enquadramento e ao individualismo, tão almejados pela modernidade, ao expandi-lo e erodir suas bases; o desterritorializa da mera aplicabilidade e burocratização de processos aprendentes, ao considerá-lo como processo de produção coletiva povoado de enunciados e signos dos espaçostempos vividospraticados dentro e fora dos cotidianos escolares.

\section{ERODINDO O CONCEITO DE PLANEJAMENTO DOCENTE}

O pensamento moderno ansioso por conservação, estagnação, por desviar a vida de seu fluxo (DELEUZE, GUATTARI, 1995a) tem buscado pela fixação de "verdades" cujos propósitos são tornar os porvires da vida previsíveis, absolutizando-os em regras. O que por vezes anula as riquezas das experiências imprevisíveis, inviabilizando os acontecimentos, pois segundo Larrosa (2002, p. 22), se pautam na aliança perversa entre informação e opinião, que se sacralizam, ao ocupar todo espaço do acontecer, formando "[...] um sujeito fabricado e manipulado pelos aparatos da informação e da opinião, um sujeito incapaz de experiência”. Soberanos de si, individualizados, apartados uns dos outros, tornando a busca por eficiência em suas ações e a estabilidade da/na vida objetivo primeiro de suas existências.

Sujeitos de uma sociedade com forte desprezo pelo que muda, difere e se transforma classificados como desvios, exceções às regras - em que impera um anseio conservador por habitar um mundo racionalizado, de determinismos regidos por regras dedutíveis e aplicáveis e que tende a desprezar o inédito que transborda da vida. Vida que não cessa de escapar e produzir possíveis fissuras nas estruturas que tentam aprisioná-la/ordená-la - em movimentos astuciosos, autorais, insurgentes e arredios através das/os praticantespensantes dos diferentes espaçostempos em que ela, a vida, acontece e prolifera. A despeito das regras impostas pela racionalidade moderna.

Uma razão indolente que, como afirma Boaventura de Sousa Santos (2006), age de maneira preguiçosa, negligente e insensível ao que dela diverge; e que na educação anseia conformar docências cada vez mais técnicas, cumpridoras de planos, não-inventivas e que não se permitem ensaiar outras possibilidades existenciais. Razão que é metonímica, pois comprime a complexidade da vida ao tomar "[...] a parte pelo todo, porque tem um conceito de totalidade feito de partes homogêneas, e nada do que fica fora dessa totalidade interessa" (SANTOS, B., 2007, p. 25-26). Desinteressada pela heterogeneidade e pelo que difere, considera as diferenças como desviantes, estrangeiras no território demarcado como do saber legítimo e, portanto, fixa sobre toda e qualquer diferença o rótulo do não-saber.

Negligente e insensível, essa racionalidade é também proléptica, pois ficciona o que está por vir, induzindo que o nosso futuro é, e só pode ser “[...] mais crescimento econômico, é um 
tempo ideal linear que de alguma maneira permite uma coisa espantosa: o futuro é infinito" (SANTOS, B,. 2007, p. 26). O que nos isentaria de preocupações com o presente, com o vivido, pois no futuro asséptico e ascético (doutrinado, disciplinado, autocontrolado, previsível e objetivo rumo à verdade), tudo se resolveria.

Muitas pesquisas e referenciais teóricos renomados no campo da educação se alicerçam nessa racionalidade, com a compreensão do planejamento como antecipação/programação/controle do processo educativo. Segundo Vasconcellos (2015, p. 7879), "[...] planejar não é apenas algo que se faz antes de agir, mas é também agir em função daquilo que se pensou.". Ação de programar a docência, "[...] um processo de racionalização, organização e coordenação da ação docente, articulando a atividade escolar e a problemática do contexto social" (LIBÂNEO, 1994, p. 222), na ânsia de planejar a ação a ser efetuada de modo a torná-la eficiente mitigando imprevistos. Eficiência medida por processos de avaliação e que será considerada tanto maior quanto mais rápido os imprevistos puderem ser neutralizados pelo planejado.

O que remonta "[...] a estrutura definida por Tyler: objetivos/experiências de aprendizagem/avaliação" (LOPES, MACEDO, 2011, p. 50), em que objetivos são idealizados, fixados e a partir daí as experiências de aprendizagem mais propícias são pensadas para efetivar o alcance do objetivado, roteirizado. Efetivação mensurada por meio de testes que possibilitem avaliar o planejamento e as experiências de aprendizagem, visando identificar as causas dos resultados alcançados. Pois, para Tyler (apud LOPES, MACEDO, 2011, p. 50):

[...] para além da objetividade, os testes devem ser, ainda, fidedignos e válidos. Isso significa, respectivamente, que o resultado possa ser replicado e diga respeito àquilo que está sendo avaliado [...] o mais importante é que o resultado de sua aplicação indique pontos fortes e fracos em relação ao alcance de cada um dos objetivos estabelecidos no currículo.

Estrutura que no cotidiano escolar produz situações como esta, cartografada através da pesquisaintervenção de que trata este artigo:

[...] lá vou eu tentar responder esse questionário [da avaliação externa] pela milésima vez (Praticantepensante $\mathrm{n}-1$ ).

Mas afinal o que é feito disso? Não vejo retorno nenhum disso pra escola (Praticantepensante $\mathrm{n}-1)$.

A SEDU estado divulga os resultados das provas na internet, agora esses dados de questionário dizem eles que usam para planejamento de ações da secretaria (Aprendiz-cartógrafo).

Entendi, pode até ser, mas o resultado das provas mesmo eu nunca vi, não sei nem como que a minha turma foi nas provas (Praticantepensante $\mathrm{n}-1)^{7}$.

Situação em que as/os professoras/es praticantespensantes são colocadas/os como recenseadoras/es do cotidiano escolar que vivempraticam, informando a quem define o que se deve ensinar, dos resultados obtidos nas avaliações elaboradas por esses últimos. O que reduz: toda a complexidade dos processos de ensinoaprendizagem a índices de recognição e de retenção de conteúdo; e a docência a uma atividade técnica de aplicação e recenseamento, negligenciando a autoria docente nas práticas educativas desenvolvidas cotidianamente na/pela docência.

\footnotetext{
${ }^{7}$ Para que seja possível vislumbrar a multiplicidade e a diferença de enunciados e enunciantes compondo a pesquisaintervenção, após cada enunciado disparado nos espaçostempos cartografados através de redes de conversações (CARVALHO, 2009), colocaremos a marca Praticantepensante $\mathrm{n}-1$, subtraindo a singularidade da multiplicidade constituída (DELEUZE, GUATTARI, 1995a). Afirmando a diferença sem criar identificações e mantendo a integridade dos diálogos em sua linguagem cotidiana e coloquial.
} 
Simplificação que é produto de uma razão indolente redutora do ato de aprenderensinar à aquisição e à sobreposição de conhecimentos.

Um modelo de esquematização e controle que tem sido amplamente aplicado nas redes de ensino através da oferta de manuais contendo planejamentos prontos e avaliações em larga escala para serem aplicados/executados pelas/os professoras/es, como por exemplo, os materiais oriundos do Pacto pela Aprendizagem no Espírito Santo (PAES), com instruções detalhadas sobre o quê, como e quando fazer. De modo a fixar planejamento docente e currículo como produtos a serem apenas aplicados por professoras/es, negligenciando o ensaio, desestimulando o prepararse, a pesquisa e a investigação docente, além do afetar-se com o outro nos acontecimentos, nas práticas educativas.

\section{Figura 1: Planejamento estruturado contido no material fornecido pelo PAES}

\begin{tabular}{|c|c|}
\hline $\begin{array}{l}\text { Dia _ Palavra-base: Nome próprio dos alunos } \\
\text { Material: fichas dos nomes dos alunos e Caderno de Atividades }\end{array}$ & $\begin{array}{l}\text { d) Faça perguntas do tipo: porque temos um } \\
\text { nome? Você sabe quem escolheu seu nome? } \\
\text { Você gosta do seu nome? Que outro nome } \\
\text { você gostaria de ter? } \\
\text { e) Pesquise na certidăo de nascimento como } \\
\text { está registrado o nome do aluno. }\end{array}$ \\
\hline $\begin{array}{l}\text { Professor(a): } \\
\text { - Registre no espaço abaixo o título do texto e/ } \\
\text { ou recursos (CD, DVD, livro, jornal) que você vai } \\
\text { utilizar com seus alunos. }\end{array}$ & $\begin{array}{l}\text { ATENÇÃO: A ficha do nome é um material } \\
\text { didático importantíssimo. Ferreiro (2001, p. } 110) \\
\text { chama a atenção para o significado do nome } \\
\text { próprio da criança:"Repeti muitas vezes que uma } \\
\text { das palavras fundamentais para a alfabetização } \\
\text { é o nome próprio e não há nenhuma outra } \\
\text { palavra que seja capaz de substituí-la, porque é } \\
\text { uma ampliação da própria identidade saber que } \\
\text { o nome se realiza por escrita. É um momento } \\
\text { muito peculiar do desenvolvimento, não só } \\
\text { cognitivo como emocional”. }\end{array}$ \\
\hline
\end{tabular}

Fonte: Dados da pesquisa

Nesse sentido, o planejamento docente é entendido como gestão do processo educativo, no qual "[...] para planejar é preciso ter certeza de onde se quer chegar, ou seja, qual escola se quer para os nossos alunos e qual escola é desejada pelos alunos e por toda a comunidade escolar" (FERNANDEZ, 2017, p. 38-39). Entendimento cartografado no cotidiano escolar como: "[...] sonhar, organizar, colocar em prática" (Praticantepensante n-1). Quando a avaliação não é citada, mas nota-se o planejamento docente pensado em fases com características específicas e sequenciais, ansiosas por racionalizar a docência.

Ânsia por racionalidade expressa também em enunciações que reduzem o planejar docente a ação de "[...] elaborar/traçar uma meta e buscar os recursos para alcançá-la"; "Organizar: saber o que vai fazer"; "Estruturar o conteúdo de forma que ele fique bem distribuído e que atenda aos alunos, aproximando-o ao máximo de sua realidade" (Praticantepensante $\mathrm{n}-1$ ).

Perspectiva que para Volpin (2016, p. 79) apenas toma sentido "[...] a partir do momento que o professor assume uma postura crítica com relação ao seu trabalho e conhece a historicidade que envolve a atividade educativa, [podendo então] planejar e executar o ensino sob uma perspectiva mais humanizadora”. Ação para a qual, segundo Torres (2015, p. 83), “[...] o educador 
tem que ver seu educando de uma forma mais integral e individualizada, observando sempre não somente o que ele diz e o resultado das atividades avaliativas, mas também o que seu corpo expressa". De modo a expandir o conceito de planejamento docente para além da organização com base em resultados obtidos em avaliações, importando também o que os corpos das/os praticantespensantes da docência expressam. Expansão que ganha força e vai ajudando a esgarçar com as expressões do planejamento docente enquanto produto ou ação derivada de manuais de qualquer espécie.

Uma vez que a vida em sua incomensurável complexidade, multiplicidade e riqueza de diferenças não cabe em universalismos e/ou regras de qualquer natureza, porque a todo instante ela está a se desfazer/compor/recompor, a transbordar. Pois, como afirma Espinosa (1988, p. 16), "[...] nenhum contrato anula a natureza" e a natureza da vida é multiplicar-se, transbordar a existência, re-existir às/nas formas que ela mesma cria, desfaz e recria, revezando formas e forças num mesmo plano de consistência. Algo que as vozes do cotidiano escolar expressam bem ao enunciarem que: "[...] se planejar as coisas fora pra chegar na aula e só aplicar, com certeza vai se frustrar" (Praticantepensante n-1).

Enunciado que esgarça o conceito de planejamento docente para além de pretensões engessantes e precarizantes da docência - que tencionam fazer das/os professoras/es meras/os aplicadoras/es, executora/es -, ao expressa-lo como processo aberto ao erro, ao rascunhar e ao coengendramento entre produção e efetuação de possíveis nas práticas educativas. $O$ que, conforme cartografado através da pesquisa-intervenção de que trata este artigo, se expressa com muita força nas práticas educativas alfabetizadoras:

[...] pra trabalhar com alfabetização não dá pra você definir os conteúdos, o que você vai passar, chegar lá e pronto não. Tem que ir fazendo, errando, vendo o que deu certo, pensando e refazendo o tempo todo. Tem que se reinventar o tempo todo. 'Como diz o outro': tem que ser artista (Praticantepensante $\mathrm{n}-1$ ).

Artistagem que expande o conceito de planejamento docente e o constitui como processo, uma aposta provocativa de práticas educativas que retoma o constante rascunhar (GABRIEL, 2016). Uma viagem sem roteiros, uma aventura ensaística para dentro de si mesmo, fissurando brechas para/com o novo; uma (des)estabilização nos conbecimentosignificações docentes (GABRIEL, 2016). Um "si mesmo" que não passa de agenciamento, discurso que se produz como a nossa voz, embora constitua agenciamento de discursos indiretos que nos atravessam e que vêm de outros. Agenciamento coletivo de enunciação - construção coletiva - constituído tão somente de enunciados e signos de um discurso sempre indireto (DELEUZE, GUATTARI, 1995b), sendo impossível identificar um enunciador particular pois é sempre processo mobilizado pela/na coletividade em suas redes de conversações.

Redes tecidas e potencializadas nos espaçostempos de planejamento em grupo. Como no trecho cartográfico abaixo:

[...] então gente, no primeiro dia de aula, a gente pode fazer tipo ano passado? (Praticantepensante $\mathrm{n}-1)$.

Ah, sim, ano passado a gente fez um tour pela escola com os meninos. Apresentando cada ambiente da escola: quadra, refeitório, pátio, banheiros, sala de professores e por aí vai (Praticantepensante $\mathrm{n}-1$ ).

Ah, acho que com uma aula dá, de preferência antes do recreio que aí eles estão menos agitados (Praticantepensante $\mathrm{n}-1$ ).

Ah, não, gente, eu preciso de mais tempo porque depois de apresentar a escola eu quero sentar com eles lá no pátio pra gente conversar, brincar e se conhecer (risos) (Praticantepensante $\mathrm{n}-1$ ). 
Quando se intensifica o planejamento docente constituído agenciamento coletivo de enunciação e que tem no ensaiar/planejar-se/preparar-se, acontecimento, ação criativa, de abertura produção de disponibilidade astuciosa para que nas práticas educativas, a força inventiva da docência rompa com a mera recognição e representação de verdades dadas (RODRIGUES, 2015). De modo a sobrepujar o medo de políticas ansiosas por controlar o currículo, driblando-as e produzindo-efetuando currículos processualmente inventivos e criativos de algo sempre novo aprendidoensinado (ASSANE, 2017) coletivamente com e não sobre as docências.

Isso pois, a produção e efetuação de possíveis do planejamento docente são processos de ordem simbiótica entre si (produção-efetuação) e, o acontecimento que emerge na aula em que a docência se processa como ato de ensaio e preparação - como relação, agenciamento de saberes, fazeres e poderes - assume um papel catalisador de conhecimentossignificações e da produção de outros modos de aprenderensinar que não os individualizados, estereotipados, pré-concebidos e almejados pela racionalidade indolente. Produção-efetuação que provoca a docência a repensar-se, a colocar em análise o movimento do planejar-se, preparar-se para aula e seus acontecimentos imbricados com os sujeitos praticantespensantes da/na escola. Como o enunciado a seguir, expresso por uma criança quando questionada sobre o significado de uma palavra: "bule? Sei sim, é quando a gente implica com o coleguinha" (Praticantepensante $\mathrm{n}-1$ ).

Expressão que erode o planejamento instituído via problematização, produção e expansão de diferentes conhecimentossignificações para além da alfabetização e através desta. Revisando a si mesma ante o alerta de que bule é um utensílio pouco conhecido na atualidade pelas crianças, considerando seus olhares e expressões. Enunciações que questionam as formas que a escola se produz quando não encontra conexão com o que é imanente aos estudantes. Pois, concordando com Pinar (apudLOPES, MACEDO, 2011), expressam assinaturas afirmativas de que é impossível, com sentido, desenhar/delimitar como se dará uma experiência educacional. Sendo a forte objeção a essa ideia, o fato de que não se pode predizer, prever, fechar numa organização - com certeza alguma - quais as respostas, os afetos, as intensidades daqueles que nos escutam e conosco entram em relação.

Intensidades educativas que passam pelo conceito de planejamento docente, e o compõem e transformam, por este ser da ordem experiência. Que para Larrosa (2002) constitui abertura para aquilo que nos toca, nos afeta, nos passa; para aquilo que nos move, nos transforma; como percepção, para a possibilidade de sensibilizar as/os professoras/es praticantespensantes da docência provocando tremores, afetando essas/es coautoras/es, expondo-as/os aos perigos e às mudanças; mobilizando a vida nelas/es presente a acontecer, transbordar potência.

Assim, o planejamento docente, não se limita apenas a ocupação de um território instituído por determinações, mas também se expressa pelas potências dos territórios de criação, experiência e autoria; rascunhos de mapas passíveis de rasuras/rasgos, ferramenta contra-hegemônica de resistência contra modelizações e de acionamento das dimensões conversacionais e experimentais das práticas educativas vividaspraticadas no cotidiano escolar.

\section{ENSAIAR É PRECISO}

A constituição de uma vida em sociedade provoca a ocupação, o abandono e a realocação em diferentes territórios físicos, psíquicos, sociais, políticos, culturais, ambientais, éticos, estéticos que, como apontam Deleuze e Guattari (1997), se apresentam como constantes processos de 'desre-territorializações’ que, por vezes, de modo ficcional, convidam/exigem dos indivíduos uma preparação/planejamento para a ocupação dos territórios. 
O planejar docente, pouco vislumbrado nas escolas como potencialidade para as práticas educativas, se dá cotidianamente como um rascunhar, preparo e ensaio, no sentido de Deleuze, em busca de inspiração ao invés de antecipação para os acontecimentos que emergem na aula. Como afirma Deleuze (1994), o entusiasmo em professar o que quer que seja é resultado de ensaio, o que não tem a ver com repetir algo treinado, mas sim investigar, pesquisar e impregnar-se daquilo que desejamos proferir de modo a criar em nós disponibilidade para a produção de inspiração, fascínio e encantamento pelo que professamos.

Ensaio produtor de aberturas para possibilidades, para que o inesperado nos aconteça (LARROSA, 2002) e para que re-existamos na/pela docência, mesmo diante da lógica eficienticista da educação instituída pela racionalidade moderna. Notamos, através da pesquisa intervenção cartográfica, que ao habitar territórios existenciais instituídos, a docência se estabelece e se "protege" do caos, adquirindo formas e modos de agir, que por vezes sobrecodificam as práticas educativas. Entretanto, o planejar docente também se constitui de ensaios, rascunhos e rasuras, ao se compor com as múltiplas enunciações, pensamentos, desejos, desafios e acontecimentos escolares, dito de outro modo, quando desterritorializa as prescrições, determinações e homogeneidades, elabora/cria novas possibilidades educativas e novo território existencial para os currículos e docências.

Ensaiar é, portanto, compor com os diferentes territórios. Preparar-se na/com/pela docência e mover-se entre territórios instituídos, organizacionais, burocráticos, técnicos, mas também é ocupar-se de novas aberturas, compondo com o movimento caótico, pulsante, coletivo e desejante de aprendizagens que a vida apresenta. Assim, é preciso ensaiar, pois a vida é jorro incessante de criação, o desejo em transbordo, invenção perene, processos de 'des-reterritorialização' simultâneas (DELEUZE, GUATTARI, 1997).

Desterritorializar a ideia instituída de planejamento como algo individual, solitário, técnico, burocrático, de antecipação das práticas educativas, permite a criação/ocupação de um novo território existencial para o planejamento docente. O que amplia seus sentidos para a coletividade, para aula enquanto desejo da docência, para o encontro com os estudantes e suas demandas de aprendizagens, alargando fronteiras para intensificar a vida e suas forças ao expandir conbecimentossignificaçoes. Pois, concordando com Nietzsche (2011, p. 110), o que há na vida e nos diferentes modos de ser de todo vivente é a busca por expansão, ampliação, crescimento. Sendo este o segredo que a vida confiou a Zaratustra: "[...] eu sou aquilo que sempre tem de superar a si mesmo". Desejo por expansão que, além da janela, avista um pé de pitanga e deseja fugir da sala de aula transbordando suas paredes - não por tédio ante a aula, mas porque um agenciamento se fez entre estudantes e pitangas: "[...] ao lado da minha sala, no meio daqueles matos tem um pezão de pitanga, os meninos repararam ele hoje e me pediram pra ir lá pegar umas pitangas. Menino, fui lá com eles no meio daquele mato e eles comeram foi pitanga" (Praticantepensante $n-1$ ).

Transbordamento que é agenciamento coletivo de enunciação, que é vida. Transbordamento que conecta as vozes das/os praticantespensantes da docência e mobiliza modos outros de existência e de relação entre professora e estudantes. Vozes que dependem "[...] sempre de um agenciamento de enunciação molecular, que não é dado [em uma] consciência, assim como não depende apenas de [...] determinações sociais aparentes, e que reúne vários regimes de signos heterogêneos" (DELEUZE, GUATTARI, 1995b, p. 18). Agenciamento coletivo de enunciação que, elabora-se no ensaio docente e constitui o planejamento docente produzindo possíveis nas práticas educativas a partir das múltiplas relações e acontecimentos que expressa em vozes/enunciados e signos, como neste recorte cartográfico:

[...] ano passado eu pedi pra eles desenharem sobre como foram as férias (Praticantepensante $\mathrm{n}-1$ ). 
Ah não, bora fazer uma brincadeira, uma dinâmica sei lá, já começar com papel desde o primeiro dia (Praticantepensante $\mathrm{n}-1$ ).

Desde o primeiro dia, e no segundo já tem dever (risos) (Praticantepensante n-1).

Deus me livre (Praticantepensante $\mathrm{n}-1$ ).

Tô brincando, tava pensando em cantar algumas musiquinhas todo mundo junto, tipo de boas-vindas, bom dia, boa tarde... de boas maneiras (Praticantepensante $\mathrm{n}$ $1)$.

Possíveis que, conforme Lazzarato (2006, p. 24), “[...] não constituem uma categoria abstrata que designa qualquer coisa que não existe: o mundo possível existe perfeitamente, mas não existe fora daquilo que o expressa [...] nos agenciamentos coletivos de enunciação". Para se produzirem-efetuarem, "acontecerem" a quem praticapensa a docência nas práticas educativas, exigem disponibilidade, receptividade, abertura (LARROSA, 2002). Processo que exige ensaio investigação, pesquisa, conversas e problematizações. Exige que as/os professoras/es praticantespensantes se constituam como quem "[...] investiga seus próprios movimentos em relação às suas problemáticas profissionais e perspectiva a criação pedagógica” (MATOS, SCHULER, CORAZZA, 2015, p. 227). Uma vez que "[...] o modo do acontecimento é a problematização e um acontecimento não é a solução de problemas, mas a abertura de possíveis" (LAZZARATO, 2006, p. 13-14), de possibilidades outras a se produzir nas práticas educativas através do planejamento docente, expandindo conhecimentossignificações, currículo e formação docente.

Assim, o ensaio, enquanto postura ética da docência consigo mesma e com a educação, agencia atos e signos, relações e acontecimentos de uma ordem sensível, capaz de corroer as segmentaridades que engessam as práticas educativas, compondo 'atos de currículo' afirmativos da vida em suas múltiplas potências. Atos de currículo que tornam forças invisíveis visíveis (SANTOS, I., 2014), produzindo-efetuando possíveis:

[...] eu acho que seria bacana a gente pensar o carnaval que acontece aqui na região, que é carnaval de rua (Praticantepensante $\mathrm{n}-1$ ).

É chega desse negócio de marchinha (Praticantepensante n-1).

Fala mal das marchinhas não que eu gosto (Praticantepensante $\mathrm{n}-1$ ).

Eu por mim não fazia nada (Praticantepensante $\mathrm{n}-1)$.

Uai gente, mas o carnaval tá aí, ele acontece por que não falar disso? (Praticantepensante $\mathrm{n}-1$ ).

Atos potentes em formar coletivamente as/os praticantespensantes que tem a docência como ofício através do ensaio, criando disponibilidade, abertura para viverpraticar a aula como multiplicidade de acontecimentos, "[...] o Grande Meio-dia, preparado, maduro como o bronze reluzente, como a nuvem cheia de relâmpagos e o seio cheio de leite" (NIETZSCHE, 2011, p. 206). Acontecimento que produz "[...] em primeiro lugar uma transformação da subjetividade, ou seja, da maneira de sentir: não suportamos mais aquilo que suportávamos antes, 'a distribuição dos desejos mudou' dentro da alma" (LAZZARATO, 2006, p. 11-12): "Chega de marchinhas"; "Deus me livre: dever no segundo dia de aula?".

Transformação do que há, expandindo conhecimentossignificações contextuais/territoriais transcriados (CORAZZA, 2013) em aula através da docência produzida-efetuada pelo coletivo de forças em um dado espaçotempo se encontra, entra em relação. Pois “[...] efetuar, atualizar os possíveis que vêm se expressar como potencialidades no encontro com o outro significa explicar aquilo que os mundos possíveis, as novas possibilidades de vida, implicam, desenvolver aquilo que envolvem" (LAZZARATO, 2006, p. 19). Produção de conbecimentossignificações possíveis pela autoria coletiva quando a efetuação da docência em sua "Didática-Artista", 
[...] movimenta os seus processos de pesquisa, criação e inovação. Acolhe e honra os elementos científicos, filosóficos e artísticos - extraídos de obras já realizadas, que diversos autores criaram, em outros planos, tempos, espaços -, como as suas efetivas condições de possibilidade, necessárias para a própria execução; e, ao mesmo tempo, como o privilegiado campo de experimentação, necessário para as próprias criações. Com esses elementos, constitui um campo artistador de variações múltiplas e disjunções inclusivas; que compõe linhas de vida e devires reais, pontos de vista ativos e desterritorializações afirmativas. (CORAZZA, 2013, p. 205).

O que no/pelo ensaio - envolvendo pesquisa, investigação, conversas e problematizações tecidas na/com a coletividade do planejamento docente - cria um "campo artistador", pois conforme enunciado pelas/os professoras/es: a docência "tem que ser artista". Produtora e autora daquilo que vivepratica nos cotidianos escolares em acontecimentos, efetuando mundos (LAZZARATO, 2006) e práticas educativas possíveis. Produzindo e expandindo currículos e docências em constante formação via acontecimento, em espaçostempos nos quais "[...] se compreende que é aquele em que se faz, se é, reunindo o que no passado nos levou ali e que abre ao futuro suas possibilidades" (ALVES, 2019, p. 113-114).

Aberturas propiciadas pelo ato de ensaiar tomando a docência como relação de disponibilidade para afetar e ser afetado pelo diferente, na repetição cotidiana das redes de conversações, nos acontecimentos produzidos-efetuados nos encontros com estudantes, professoras/es, com textos (institucionais ou não), com imagens, músicas, literatura "e...e...e..." (DELEUZE, GUATTARI, 1995a). Deslocando-se de convicções, de certezas, de verdades préestabelecidas; abrindo mão do lugar de poder hegemônico da/o docente que sabe e, portanto, ensina à/ao aluno que não sabe, para compor o aprenderensinar com quem praticapensa a docência e a constitui como encontro, relação e ação promotora de acontecimentos produtores-efetuadores de possíveis. E contaminando-se com a docência enquanto ato de aprenderensinar, traduzir, transcriar diferentes conhecimentossignificações - científicos, artísticos e filosóficos -, expansivos e afirmativos da vida em sua multiplicidade de sentidos e intensidades.

Ensaiar, desse modo, relaciona-se com se preparar para viverpraticar a aula, aberta/o, disponível aos possíveis por produzir-efetuar, atento aos detalhes arranjados e ao mesmo tempo improvisados, sem modelos, manuais ou mesmo métodos, mas com o entusiasmo, o encantamento de quem entra em núpcias (DELEUZE, PARNET, 1998). É planejar tencionando "se preparar para realizar algo" (Praticantepensante $\mathrm{n}-1$ ) - aula -, que quando começa vai embora, sem tempo para consultas a manuais e planos; rascunhando quando preciso os registros, rastros dos ensaios que produzem nas/os professoras/es praticantespensantes o entusiasmo pois, como nos aponta Alves (2019, p. 114):

[...] cada docente a pensa [a aula] - planejando ou não algum tempo antes (sabemos que, muitas vezes, isso é decidido na hora em que se entra na sala), tendo artefatos diversos nos quais se apoiar ou não - mas há aquele momento no qual se entra em sala e em que se sabe que [...] se tem que trazer todo o passado do que se sabe, se fez para impulsionar o que ali vai acontecer, mobilizando os estudantes para que cheguem adiante, a um futuro sempre incerto.

Dessa forma, preparar-se para a aula, ensaiar para o encontro, exige a ampliação do conceito de planejamento docente e da própria docência, ao "[...] formular algo novo para pensar; problematizar, com e diante dos alunos, o que até então não era considerado problemático por ninguém; conseguir levar os alunos a encararem as besteiras e desaprender as verdades, que lhes haviam sido transmitidas e ensinadas (CORAZZA, 2013, p. 24). 
Conceito esgarçado de planejamento docente que não se expressa como uma essência nos corpos de professoras/es praticantespensantes, mas como agenciamento coletivo de enunciação que constitui um discurso indireto, composto de múltiplos enunciados e signos disparados e produzidos numa multiplicidade de atos e acontecimentos, que atravessa os corpos de um lado a outro (DELEUZE, GUATTARI, 1995b). Não se trata de algo que pode ser transmitido consciente e intencionalmente. É algo pensado-praticado nas relações, que no sentido de Deleuze, é imanente à vida. Cabendo dessa forma, a quem tem a docência como ofício, o ensaio, a pesquisa, a investigação e a problematização do que vivepratica. Pois,

[...] como tudo, são ensaios. Uma aula é ensaiada, as/os professoras/es praticantespensantes pesquisam lendo livros variados, artigos, assistem filmes, vídeos na internet, palestras, ouvem músicas e conversam entre si tencionando abrir-se, preparar-se para as núpcias que a aula pode promover. É como no teatro e nas cançonetas, há ensaios. Se não tivermos ensaiado - investigado, pesquisado, conversado e problematizado - bastante, não estaremos inspirados. Uma aula quer dizer momentos de inspiração, senão não quer dizer nada" (DELEUZE, PARNET, 1994). ${ }^{8}$

Inspiração produzida mais do que recebida, agenciamento na produção-efetuação de currículos e docências outras, como narrado no trecho cartografado que segue:

[...] ontem eu estava ensinando matemática. Aí falando dos números e tal - vem umas coisas malucas na cabeça da gente de vez em quando né? - inventei uma atividade ali na hora mesmo e eles gostaram menino. Eu escrevi um monte de números no quadro e aí depois ia falando e eles iam apontando, depois riscando no caderno... olha foi muito bacana. Inventamos ali na hora (Praticantepensante $\mathrm{n}-$ 1).

É preciso, portanto, ensaiar tencionando produzir inspiração, pensar a aula e a docência sem a pretensão desesperadora de tentar antecipar o que está por vir, comprimindo o presente e dilatando o futuro prolepticamente (SANTOS, B., 2007). Trata-se de preparar-se, tornar-se disponível para viverpraticar a aula e a docência, forçando a produção e expansão de diferentes conbecimentossignificaçoes, estremecendo o instituído, problematizando, acontecendo com a aula e com/pela/na docência. Tendo em vista que "[...] é preciso achar a matéria da qual tratamos, a matéria que abraçamos, fascinante. Às vezes, temos de nos açoitar [...] é necessário chegar ao ponto de falar de algo com entusiasmo. O ensaio é isso"" (DELEUZE, PARNET, 1994), é criar disponibilidade para que "coisas malucas" venham à cabeça nos forçando a inventar, a produzirefetuar possíveis nas práticas educativas.

Já que, concordando com Gilles Deleuze em entrevista a Claire Parnet (1994), “[...] as aulas são algo muito especial. Uma aula é um cubo, ou seja, um espaço-tempo. Muitas coisas acontecem numa aula [...] uma aula é algo que se estende de uma semana a outra. É um espaço e uma temporalidade muito especiais. Há uma sequência" ${ }^{\prime 10}$. Espaçotempo sempre entre, com prolongamentos para frente e para trás, tempo presente dilatado que não anseia por organizar, plantar, planificar o futuro, mas aposta no presente como futuro imediato.

Ensaiar, planejar-se, preparar-se para a aula se constitui, assim, pela composição de docências outras, que mobilizam currículos outros, sedentos por produzir conhecimentossignificações expansivos de conceitos, os quais só têm sentido de existir quando tem utilidade em nossas vidas,

\footnotetext{
${ }^{8}$ Trecho retirado de entrevista em formato de vídeo, portanto, não paginado.

${ }^{9}$ Ibidem.

${ }^{10}$ Ibidem.
} 
quando estão em pleno uso ou na iminência disso, como ferramentas que se aprimoram conforme o uso. É preciso que os conceitos funcionem, que sirvam. Conceitos que “[...] não nascem prontos, não andam pelo céu, não são estrelas, não são contemplados. É preciso criá-los, fabricá-los"11 (DELEUZE, PARNET, 1994), problematizá-los para fazer com que algo aconteça, produzirefetuar possíveis.

\section{PLANEJAR É RE-EXISTIR}

Estes escritos constituem fragmento, de uma pesquisa-intervenção que cartografou erodindo, fissurando, produzindo aberturas nas diversas expressões - assinaturas que o conceito de planejamento docente assume no cotidiano escolar tencionando esgarça-lo até o limite de cartografá-lo como produtor de possíveis nas práticas educativas. O que foi possível através de uma investigação cartográfica erosiva/expansiva de expressões/assinaturas que enunciam o planejamento docente como possibilidade de criação assim como aquelas que o expressam como mera organização, planificação de um futuro a ser praticado tal e qual o idealizado. O que se dá principalmente por meio de instrumentos organizativos instituídos e pretensamente capazes de prever o futuro: planos de ensino (trimestral, anual etc.), espaçostempos de planejamento (individual, coletivo, com assessoria pedagógica), planos de aula, caderno de planejamento e planners (caderno com uma série de informações e organizações pré-fabricadas, espécie de guia para planejar aulas). Formas instituídas que tendem a apaziguar a docência, livrando-a das "açoitadas" dos ensaios de preparação, pesquisa, investigação, conversa e problematização produtores de inspiração e disponibilidade aos acontecimentos, e que por vezes encontram forte adesão entre as professoras/es.

Afinal, trata-se de uma categoria há muito afligida por baixos salários, péssimas condições estruturais/materiais de trabalho, quantitativo de alunas/os incompatíveis com a natureza educativa demandada, jornadas múltiplas de trabalho - em espaçostempos múltiplos e nem sempre próximos e ou de percurso de fácil deslocamento. O que ameaça a vida de quem tem a docência como ofício diariamente, sendo tentadoras as formas instituídas que prometem conservar a vida com materiais para simples execução, ainda que seja reduzindo a profissão docente à execução, aplicação de prescrições.

Estratégias de uma racionalidade que produz frustração com relação à docência, dada a impossibilidade de adequar o cotidiano escolar a uma organização previamente idealizada - fora dele e que tenciona agir sobre ele -, negativa da vida em sua multiplicidade de intensidades e sentidos. Racionalidade burocratizante que se expressa fortemente nos instrumentos de avaliação padronizados.

O que solicita das/os professoras/es praticantespensantes, a despeito das adversidades, a astúcia de re-existir como autoras/es das/nas práticas educativas que vivempraticam e produzem cotidianamente. Ação que exige ensaio, preparação, criação de disponibilidade e exige viverpraticar o planejamento docente como produção de possíveis nas práticas educativas. Práticas educativas potentes em promover o transbordar da vida em suas multiplicidades de intensidades e sentidos. Invenções produzidas a partir do que existe, desejo que por ser criação, expansão, transbordamento, jorro de vida, "[...] é revolucionário porque quer sempre mais conexões e agenciamentos" (DELEUZE, PARNET, 1998, p. 64).

Desejo de compor, expandir, produzir conhecimentossignificações, currículos e docências possíveis, ensaísticas, problematizadoras, pesquisadoras e autoras do que se produz-efetua nos

\footnotetext{
11 Ibidem.
} 
acontecimentos vividospraticados pelas/os praticantespensantes da docência. Desejo, por ser praticantepensante ao invés de apenas praticante ou somente pensante, de como

[...] professor, [...] conseguir dar uma aula como Dylan organiza uma canção, surpreendente produtor, mais que autor. E que comece como ele, de repente, com sua máscara de palhaço, com uma arte de cada detalhe arranjado e, no entanto, improvisado. O contrário de um plagiador, mas também o contrário de um mestre ou de um modelo. Uma preparação bem longa, mas nada de método nem de regras ou receitas. Núpcias, e não casais nem conjugalidade (DELEUZE, PARNET, 1998, p. 8).

Em um processo contínuo de produção, erosão e reconstrução. Núpcias com o que nos afeta, que nos atravessa, nos acontece/passa, que produzimos-efetuamos, que da vida encontramos para além de representações e simulacros. Docências vividaspraticadas no cotidiano escolar entre praticantespensantes produzindo-efetuando possíveis nas/pelas práticas educativas de aprenderensinar das quais são produtores-autores.

Posto isto, a potência do planejamento docente pelo viés do ensaio e dos agenciamentos coletivos de enunciação afirma-se como um modo de resistência ao enquadramento e ao individualismo tão almejados pela racionalidade moderna. Ao expandi-lo e erodir suas bases, o expressamos como processo produzido coletivamente, povoado de enunciados e signos dos espaçostempos vividospraticados dentro e fora dos cotidianos escolares. Processo potencializado pelo ensaio, portanto: é necessário ensaiar, preparar-se longamente, para que algo aconteça. Pois, quem sabe assim, seja possível re-existir na/pela docência?

\section{REFERÊNCIAS}

ABRANCHES, Graça. Guia para uma linguagem promotora da igualdade entre mulheres e homens na administração pública. Lisboa: Comissão para a Cidadania e Igualdade de Género, 2009. Disponível em

https://www.cig.gov.pt/wpcontent/uploads/2015/11/Guia ling mulhe homens Admin Publica.pdf. Acesso em 4 abr. 2020.

ALVES, Nilda. Práticas pedagógicas em imagens e narrativas: memórias de processos didáticos e curriculares para pensar as escolas hoje. São Paulo: Cortez, 2019.

ASSANE, Adelino Inácio. Práticas curriculares no ensino básico: tecendo e narrando redes de experiências na formação continuada dos professores da disciplina de Ofícios em Moçambique. 2017. 306 f. Tese (Doutorado em Educação) - Faculdade de Educação, Universidade Federal Fluminense, Niterói, 2017.

CARVALHO, Janete Magalhães. Cotidiano escolar como comunidade de afetos. Petrópolis: DP et Alii, 2009.

CORAZZA, Sandra Mara. O que se transcria em educação? Porto Alegre: Doisa, 2013.

DELEUZE, Gilles; GUATTARI, Félix. Mil platôs: capitalismo e esquizofrenia. Tradução de Aurélio Guerra Neto e Célia Pinto Costa. Rio de Janeiro: Ed. 34, 1995a. 1 v.

DELEUZE, Gilles; GUATTARI, Félix. Mil platôs: capitalismo e esquizofrenia. Tradução de Ana Lúcia de Oliveira e Lúcia Cláudia Leão. Rio de Janeiro: Ed. 34, 1995b. 2 v.

DELEUZE, Gilles; GUATTARI, Félix. Mil platôs: capitalismo e esquizofrenia. Tradução de Suely Rolnik. São Paulo: Ed. 34, 1997. 4 v. 
DELEUZE, Gilles; PARNET, Claire. O abecedário Deleuze. Produção: Direção: Pierre-André Boutang. Entrevistadora: Claire Parnet. Exibido no Brasil pelo Ministério da Educação no canal TV Escola. Tradução e legendas: Raccord. Documentário. Paris: Éditions Montparnasse, 1994. 1 DVD (453min).

DELEUZE, Gilles; PARNET, Claire. Diálogos. Tradução de Eloísa Araújo Ribeiro. São Paulo: Escuta, 1998.

ESPINOSA, Baruch. Tratado teológico-politico. Tradução de Diogo P. Aurélio. Lisboa: Imprensa Nacional - Casa da Moeda, 1988.

FERNANDEZ, Gilne Gardesani. Planejamento na prática docente da rede municipal de Santo André- SP. 2017. 128 f. Dissertação (Mestrado em Educação) - Programa de Mestrado em Educação, Universidade Cidade de São Paulo, São Paulo, 2017.

GABRIEL, Karla Aparecida. De cartas em cartas: o planejamento das aulas de professoraspraticantes dos primeiros anos do ensino fundamental da rede municipal de Juiz de Fora, numa perspectiva de experiência em Jorge Larrosa. 2016. 174 p. Dissertação (Mestrado em Educação) - Programa de Pós-Graduação em Educação, Universidade Federal de Juiz de Fora, Juiz de Fora, 2016.

LARROSA, Jorge. Notas sobre a experiência e o saber da experiência. Revista Brasileira de Educaşão, Campinas, n. 19, p. 20-28, jan./abr. 2002. Disponível em https://www.scielo.br/pdf/rbedu/n19/n19a02.pdf. Acesso em 2 jul. 2020.

LAZZARATO, Maurizio. As revoluções do capitalismo. Tradução de Leonora Corsini. Rio de Janeiro: Civilização Brasileira, 2006.

LIBÂNEO, José Carlos. Didática. São Paulo: Cortez, 1994.

LOPES, Alice Casimiro; MACEDO, Elizabeth. Teorias de currículo. São Paulo: Cortez, 2011.

MATOS, Sônia Regina da Luz; SCHULER, Betina; CORAZZA, Sandra Mara. Formação do professor-pesquisador: aprendizado que afirma a vida. Revista da FAEEBA - Educação e Contemporaneidade, Salvador, v. 24, n. 43, p. 225-236, jan./jun. 2015. Disponível em https://www.revistas.uneb.br/index.php/faeeba/article/viewFile/1330/909. Acesso em 2 jul. 2020.

NIETZSCHE, Friedrich. Assim falou Zaratustra: um livro para todos e para ninguém. Tradução de Paulo César de Souza. São Paulo: Cia. das Letras, 2011.

OLIVEIRA, Inês Barbosa de. Currículos e pesquisa com os cotidianos: o caráter emancipatório dos currículos 'pensadospraticados' pelos 'praticantespensantes' dos cotidianos das escolas. In: FERRAÇO, Carlos Eduardo; CARVALHO, Janete Magalhães (orgs.). Currículos, pesquisas, conhecimentos e produção de subjetividades. Petrópolis: DP et al., 2012. p. 47-70.

PASSOS, Eduardo; BARROS, Regina Benevides de. A cartografia como método de pesquisaintervenção. In: PASSOS, Eduardo; KASTRUP, Virgínia; ESCÓSSIA, Liliana (org.). Pistas do método da cartografia: pesquisa-intervenção e produção de subjetividade. 4. ed. Porto Alegre: Sulina, 2015. p. 17-31.

RODRIGUES, Larissa Ferreira. Entre imagens cinema e imagens escola, movimentando o pensamento com a formação de professores. 2015. 233 f. Tese (Doutorado em Educação) - Programa de Pós-Graduação em Educação, Universidade Federal do Espírito Santo, Vitória, 2015.

SANTOS, Boaventura de Sousa (org.). A gramática do tempo: para uma nova cultura política. São Paulo: Cortez, 2006.

SANTOS, Boaventura de Sousa (org.) Renovar a teoria crítica e reinventar a emancipação social. São Paulo: Boitempo, 2007. 
SANTOS, Igor Alexandre de Carvalho. Currículo riz̧omático e formação: “um pouco de possível, senão eu sufoco". 2014. 101 f. Dissertação (mestrado) - Faculdade de Educação, Universidade Federal da Bahia, 2014.

TORRES, Simone Pádua. A corporeidade no ensino fundamental: na busca de uma educação emancipatória. 2016. 93 f. Dissertação (Mestrado em Educação) - Programa de Pós-Graduação em Educação-Mestrado Profissional, Universidade Federal de Lavras, Lavras, 2016.

VASCONCELLOS, Celso S. Planejamento: Projeto de ensino-aprendizagem e projeto políticopedagógico. 25. ed. São Paulo: Ed. Libertad, 2015.

VOLPIN, Gizeli Beatriz Camilo. O significado e o sentido do planejamento no trabalho do professor: uma análise crítica a partir da teoria da atividade de A.N. Leontiev. 2016. 151 f. Dissertação (Mestrado em Educação Escolar) - Faculdade de Ciências e Letras, Universidade Estadual Paulista Júlio de Mesquita Filho, Araraquara, 2016.

Submetido em agosto de 2020

Aprovado em novembro de 2020

\section{Informações do(a) autor(a)}

Izaque Moura de Faria

Universidade Federal do Espírito Santo

E-mail:izaque.faria@gmail.com

ORCID: https://orcid.org/0000-0001-8374-2365

Link Lattes: http://lattes.cnpq.br/5905499802446337

Larissa Ferreira Rodrigues Gomes

Universidade Federal do Espírito Santo

E-mail: larirodrigues22@hotmail.com

ORCID: http://orcid.org/0000-0002-3256-2652

Link Lattes: http://lattes.cnpq.br/8966483295370868 